Patients' perspective of telephone visits during COVID-19

\title{
Patients' perspective of telephone visits during the COVID-19 pandemic
}

Jennifer Locke; Sender Herschorn; Sarah Neu; Laurence Klotz; Ron Kodama;

Lesley Carr

Sunnybrook Health Sciences Centre, University of Toronto, Toronto, ON, Canada

Cite as: Can Urol Assoc J 2020 June 25; Epub ahead of print. http://dx.doi.org/10.5489/cuaj.6758

Published online June 25, 2020

$* * *$

\section{Abstract}

Introduction: With the cessation of non-urgent clinical office visits due to the coronavirus, there has been a rapid shift to telephone and other virtual visits in outpatient practice. We conducted a survey to evaluate patients' perspective of telephone visits during the COVID-19 pandemic.

Methods: Patients receiving a scheduled telephone call, as a virtual visit, from urologists at our clinic were asked to participate in a three-minute, self-administered, online questionnaire. After verbal permission was obtained, the survey was emailed to each participant. The outcomes evaluated were telephone visit satisfaction and preference for type of appointment. Non-parametric tests were used to analyze the results. The study was approved by the Sunnybrook Research Ethics Board.

Results: A total of 102 participants were included; 96\% of participants assessed the telephone visit as a positive experience in every survey question, while $45 \%$ expressed no preference. In those who expressed a preference, this was evenly divided between inoffice visits and phone visits ( $\mathrm{p}=0.0614)$. Participants who lived more than $75 \mathrm{~km}$ from the hospital were less likely to prefer an in-office visit compared to those residing locally ( $U=433 ; p=0.006$; odds ratio $0.29 ; 95 \%$ confidence interval $0.106-0.779 ; p=0.0142$ ).

Conclusions: In this survey, most participants assessed the telephone visit positively. Almost half had no preference and a similar proportion expressed a preference for inoffice and telephone visits. Patients who resided farther from the hospital were more likely to prefer the telephone visit. This is the first study that we know of to assess patients' preferences regarding remote encounters in urology. 
Patients' perspective of telephone visits during COVID-19

\section{Introduction}

The World Health Organization (WHO) declared COVID-19 a global pandemic on March 11, 2020 and recommended, "rapid, robust and rigorous containment of the COVID-19 outbreak through physical distancing and hospital preparedness, coordination and health sector planning". As part of the preparedness to limit spread of COVID-19, Canadian physicians closed their offices to the public for non-urgent care. To facilitate healthcare access for patients in Ontario, the Ontario Ministry of Health released a temporary list of Ontario Health Insurance Plan (OHIP) fee codes that cover assessments of/or counselling to insured persons by telephone or video. ${ }^{2}$ In the United States, telephone and video visits have been rapidly integrated into urology practice. ${ }^{3-7}$ Similarly, in Northern Italy, patients with non-urgent conditions were consulted via telephone as a way of maintaining care during the pandemic. ${ }^{6}$

The telephone visit, as an alternative to in the in-person visit, has been evaluated in general practice. In a systematic review of 2 systematic reviews and 1 randomized controlled trial, Downes et al. concluded that there is a lack of high level evidence for the benefit of telephone consultations in a general practice (GP) setting; however, they may be an alternative to face-to-face consultations in certain settings. ${ }^{8}$ In a mixed-methods case study Atherton et al. sought to assess under what conditions, for which patients and in what ways the telephone, email or internet video visits may offer benefit to patients and practitioners in general practice as compared to the in-person visit. ${ }^{9}$ The authors found that email and internet video communication with patients were associated with provider resistance and were not being practiced widely in the United Kingdom. The telephone visit was the only alternative to the in-person visit in common use. Patients appreciated the efficiency and convenience of the telephone visit, but for certain conditions preferred an in-person visit.

With the cessation of in-office visits telephone visits have served as a replacement. We could find no publications about the perception of telephone visits by urology patients. Hence we conducted a patient survey using a short questionnaire ${ }^{10}$ to evaluate the patient's perspective of the telephone visit during the COVID-19 pandemic.

\section{Methods}

At the onset of physical distancing and hospital preparedness recommendations, telephone visits were offered in our urology clinic by 5 urologists with expertise in general urology and sub-specialties of functional urology and uro-oncology. Patients received a telephone call from their physician at a scheduled time. Patients included were those scheduled in every outpatient clinic from April 20 to May 9, 2020 (consecutively). At the end of the telephone visit each patient was asked if he/she would be willing to participate in a 3-minute questionnaire regarding his/her experience with the telephone visit. Once verbal permission was obtained a copy of the consent form and link to the 
online survey (Appendix; available at cuaj.ca) were emailed to each participant within 48 hours of the visit. The online survey consisted of 13 questions. The first question served as consent. The following 4 questions captured demographics. The remaining 8 questions focused on the patient's perspective of the telephone visit and were obtained from a short questionnaire, The Short Questionnaire for Out-of-Hours Care. ${ }^{10}$ This questionnaire was developed for patients receiving care through the telephone at a primary care centre and included demographic details, questions about the type of service received, whether the patient received the type of service they wanted, questions about satisfaction, and an open question inviting general comments. ${ }^{11}$ Participant survey data were collected with SurveyMonkey®. No personal or identifying information was solicited in the online survey, thus ensuring participant anonymity. The study was approved by the Sunnybrook Health Sciences Centre Research Ethics Board.

The measured outcomes were the level of patient satisfaction with the telephone visit and their preference for the in-person visit versus the telephone visit, based on fivepoint Likert-type scales. Variables assessed to predict patient satisfaction and visit preference included age, gender, proximity to the hospital (within the Greater Toronto Area (GTA) or outside of the GTA; i.e. a $75 \mathrm{~km}$ radius), and the type of appointment (first visit, routine follow-up, follow-up for test results, or procedure counselling). All variable data were reported by the patient in the survey answers.

Descriptive statistics were used to analyze patient demographic information. Nonparametric tests were used to analyze the effect of individual demographic variables on our ordinal Likert-type scale outcomes (Mann-Whitney U test and Kruskal-Wallis test). Multivariate ordered logistic regression analysis was used to assess the combined influence of interval and categorical variables on our ordinal Likert-type scale outcomes. Statistical significance was defined as $\mathrm{p}<0.05$. Data analysis was completed using IBM® SPSS software.

\section{Results}

Sixty-eight percent of patients who were emailed the link completed the survey with a $100 \%$ response rate for consent, type of visit, demographics, and preference questions 1-5 and 7 (Figure 1), 96\% response rate for satisfaction question 6 (Figure 2) and $74 \%$ for the optional narrative comments (question 8).

\section{Demographics}

One-hundred and two participants were included in the study (Table 1). Sixty-four percent were male. The median age of the participants was 65 (IQR 55-71). The type of visit was 'routine follow-up' for 53\% of the participants. Eighty-three percent lived within the GTA and $17 \%$ lived outside of the GTA. 
Patients' perspective of telephone visits during COVID-19

\section{Participant responses regarding telephone visit experience}

The majority of participants $(96 \%)$ viewed the telephone visit positively as shown in Figure 1. In Figure 2, the results from question 7 are depicted. There was no significant difference between those who expressed a preference for one type of visit over another (in-office $(21 \%)$ vs. telephone $(34 \%)(\mathrm{p}=0.0614))$.

\section{Relationships between demographic variables and preference for in-office visit}

There were no statistically significant differences for age, gender, and type of visit on preference for the in-office visit (Table 2). On multivariable regression participants who lived outside of the GTA were less likely to prefer an in-office visit to those residing locally (U=433, p=0.006; OR 0.29 (95\% CI 0.106-0.779), p=0.0142) (Table 3).

\section{Participant comments}

Qualitative assessment of the 75 participants who provided narrative comments revealed that the majority were in favour of telephone visits $(\sim 75 \%)$. The remaining provided neutral or negative comments. Two participants suggested face-to-face interaction using Zoom or other technology or online video methods for future visits. Some participants noted limitations of the telephone visit including inability to see imaging results with the doctor, provide a sample, or undergo a procedure. Many participants cited advantages including no travel time, parking cost, or wait time at the hospital.

\section{Discussion}

In this study patients' perspectives of the telephone visit during the COVID-19 pandemic were sought with a self-administered online questionnaire. We found that regardless of age, gender, proximity to the hospital and type of visit, the telephone visit was positively assessed with respect to patient satisfaction. This was further exemplified by positive narrative comments. Many of the participants cited advantages including no travel time, parking cost, or wait time at the hospital.

Although the majority of participants assessed the telephone visit as a positive experience, $45 \%$ did not have any preference for either the telephone visit or an in-person visit, and similar proportions favoured one over the other (Figure 2). This is consistent with the findings by Atherton et al. who found that participants in general practice appreciated the efficiency and convenience of the telephone visit, but for certain conditions preferred an in-person visit. ${ }^{9}$ We analyzed the data to identify predictors for those patients who preferred a telephone versus an in-office visit and found that participants who lived outside of the GTA were less likely to prefer an in-office visit as compared to those who lived within the GTA.

Although we did not quantify the narrative comments, which were provided by almost three quarters of the patients, most of them were supportive and gave us good insight into the patients' perspectives. There were definite cost advantages to a telephone 
visit including no parking or travel cost. There were time savings including travel time and wait time. Participants indicated that there are circumstances when an in-person office visit is needed or preferable, such as the first visit, seeing and reviewing imaging, providing a sample, or undergoing a procedure. Participants also indicated that the telephone visit is appropriate when no physical exam is required or when the visit is for routine follow-up.

There are limitations to this study. Firstly, this study was conducted through email so there is an inherent selection bias; patients without a computer and internet access could not be included in the study. Secondly, this study was conducted in a single site with a quaternary care referral base and therefore cases may have higher complexity. Results therefore may not be representative of the entire population. Furthermore, there is no long-term follow-up to assess the clinical outcomes of the telephone interaction. The survey sampled only patients and not physicians and we did not evaluate other virtual visit methods such as internet video.

It is unclear if the telephone visit will be funded after the COVID-19 pandemic. The use of virtual care during the pandemic has likely increased substantially and the telephone visit appears to have applicability to most types of visits. Our study suggests that the telephone visit is an excellent alternative to an in-person visit for routine followup and when a physical exam is not required, although the patients rated it highly for all types of clinic visits. Furthermore, many patients identified associated cost savings. It is possible that if telephone and virtual visits remain prevalent post-COVID, the cost savings to patients may result in revenue loss for hospitals and other medical facilities that depend on high volume out-patient traffic. As an example, in 2018-2019 there were 619,856 ambulatory clinic visits to Sunnybrook Hospital ${ }^{18}$ which generated part of the $\$ 165,168,000$ in ancillary revenue from Hospital pharmacies and leasing revenue from parking and gift shops. ${ }^{19}$ Loss of this revenue will require considerable institutional adjustment.

\section{Conclusions}

In this survey, participants assessed the telephone visit positively during the COVID-19 pandemic. Almost half had no preference and similar proportions preferred in-office versus a telephone visit. However, patients who live more than $75 \mathrm{~km}$ from the hospital were more likely to prefer a telephone visit. This is the first study that we know of to assess patients' response to non-office encounters in urology. Future studies are warranted to delineate the role of telephone visits in urology in the post-COVID-19 era. 
Patients' perspective of telephone visits during COVID-19

\section{References}

1. Kluge H. Statements, press and ministerial briefings. We can beat COVID-19 virus through solidarity Web site. http://www.euro.who.int/en/healthtopics/health-emergencies/coronavirus-covid-19/statements. Published 2020. Accessed May 26, 2020, 2020.

2. Ontario. Ministry of Health. Changes to the Schedule of Benefits for Physicians' Services in response to COVID-19 influenza pandemic. http://www.health.gov.on.ca/en/pro/programs/ohip/bulletins/4000/bul4745.pdf. Published 2020. Accessed May 24, 2020, 2020.

3. Ficarra V, Novara G, Abrate A, et al. Urology practice during COVID-19 pandemic. Minerva Urol Nefrol. 2020.

4. Smith WR, Atala AJ, Terlecki RP, Kelly EE, Matthews CA. Implementation Guide for Rapid Integration of an Outpatient Telemedicine Program During the COVID-19 Pandemic. J Am Coll Surg. 2020.

5. Gadzinski AJ, Gore JL, Ellimoottil C, Odisho AY, Watts KL. Implementing Telemedicine in Response to the COVID-19 Pandemic. J Urol. 2020:101097JU0000000000001033.

6. Luciani LG, Mattevi D, Cai T, Giusti G, Proietti S, Malossini G. Teleurology in the Time of Covid-19 Pandemic: Here to Stay? Urology. 2020.

7. Mann DM, Chen J, Chunara R, Testa PA, Nov O. COVID-19 transforms health care through telemedicine: evidence from the field. J Am Med Inform Assoc. 2020.

8. Downes MJ, Mervin MC, Byrnes JM, Scuffham PA. Telephone consultations for general practice: a systematic review. Syst Rev. 2017;6(1):128.

9. Atherton $\mathrm{H}$, Brant $\mathrm{H}$, Ziebland $\mathrm{S}$, et al. The potential of alternatives to face-toface consultation in general practice, and the impact on different patient groups: a mixed-methods case study. Health Serv Deliv Res. 2018;6(20).

10. Salisbury C, Burgess A, Lattimer V, et al. Developing a standard short questionnaire for the assessment of patient satisfaction with out-of-hours primary care. Fam Pract. 2005;22(5):560-569.

11. McKinley RK, Manku-Scott T, Hastings AM, French DP, Baker R. Reliability and validity of a new measure of patient satisfaction with out of hours primary medical care in the United Kingdom: development of a patient questionnaire. BMJ. 1997;314(7075):193-198.

12. Punia V, Nasr G, Zagorski V, et al. Evidence of a Rapid Shift in Outpatient Practice During the COVID-19 Pandemic Using Telemedicine. Telemed J E Health. 2020.

13. Boehm K, Ziewers S, Brandt MP, et al. Telemedicine Online Visits in Urology During the COVID-19 Pandemic-Potential, Risk Factors, and Patients' Perspective. Eur Urol. 2020.

14. O'Gorman LD, Hogenbirk JC, Warry W. Clinical Telemedicine Utilization in Ontario over the Ontario Telemedicine Network. Telemed J E Health. 2016;22(6):473-479. 
15. Brown EM. The Ontario Telemedicine Network: a case report. Telemed $J$ E Health. 2013;19(5):373-376.

16. 2015 Canadian Telehealth Report. Canada's Health Informatics Association. https://livecare.ca/sites/default/files/2015\%20TeleHealth-Public-eBook-Final-109-15-secured.pdf. Published 2015. Accessed.

17. Thelen-Perry S, Ved R, Ellimoottil C. Evaluating the patient experience with urological video visits at an academic medical center. Mhealth. 2018;4:54.

18. Sunnybrook. Hospital Facts and Figures 2018-2019. https://sunnybrook.ca/content/?page=statistics. Published 2019. Accessed May 28, 2020.

19. PricewaterhouseCoopers. Sunnybrook Health Sciences Centre Consolidated Financial Statements, March 31, 2019. https://sunnybrook.ca/uploads/1/welcome/about/190331-signed-shscconsolidated-financial-statements.pdf. Accessed May 28, 2020. 


\section{Figures and Tables}

Fig. 1. Preference question.

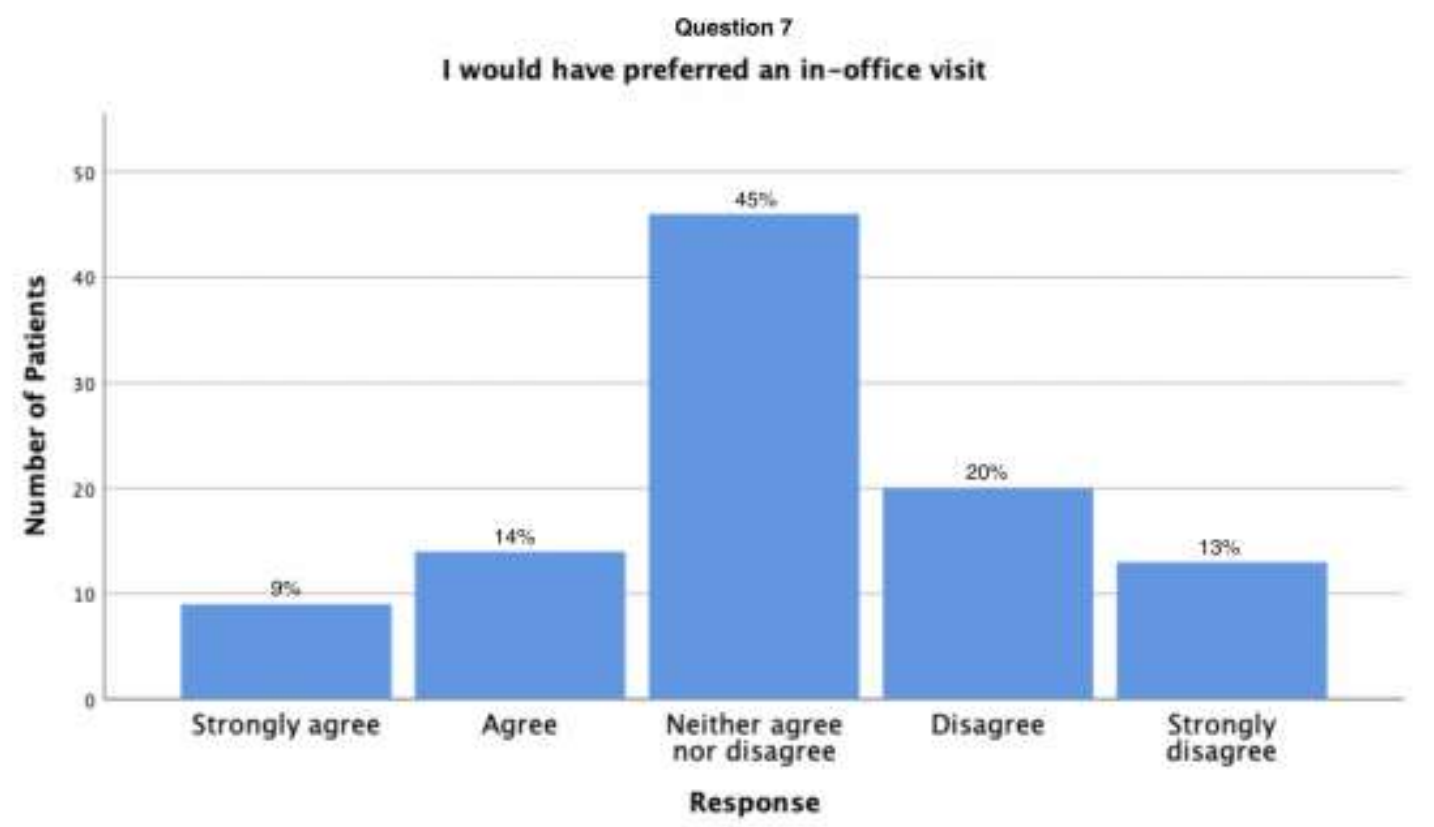

Fig. 2. Satisfaction questions.

The time you had to wait before you finally spoke to a docto

The way your phone call was arrange

ฮั

The attitude of the docto

The explanation the doctor gave you about your problem

The treatment or advice you were given

Overall, how satisfied were you with the service received? 
Patients' perspective of telephone visits during COVID-19

\begin{tabular}{|l|c|}
\hline Table 1. Demographic characteristics of study participants \\
\hline Demographic variable & $\begin{array}{c}\text { Patient cohort } \\
\mathbf{n = 1 0 2}\end{array}$ \\
\hline Age & $62.2(14.2)$ \\
\hline Mean (SD) & $65.5(55-71)$ \\
\hline Median (IQR) & \\
\hline Gender, $\mathrm{n}(\%)$ & $66(64.7)$ \\
\hline Male & $36(35.3)$ \\
\hline Female & $84(82.3)$ \\
\hline Proximity to hospital & $18(17.6)$ \\
\hline Within GTA, $\mathrm{n}(\%)$ & \\
\hline Outside of the GTA, $\mathrm{n}(\%)$ & $19(18.6)$ \\
\hline Type of visit & $54(52.9)$ \\
\hline First visit, $\mathrm{n}(\%)$ & $10(9.8)$ \\
\hline Routine followup, $\mathrm{n}(\%)$ & $14(13.7)$ \\
\hline Followup test results, $\mathrm{n}(\%)$ & $5(4.9)$ \\
\hline To discuss a procedure, intervention or surgery, $\mathrm{n}(\%)$ & \\
\hline Other, $\mathrm{n}(\%)$ & \\
\hline
\end{tabular}


Patients' perspective of telephone visits during COVID-19

\begin{tabular}{|c|c|c|c|c|c|c|c|c|}
\hline & & $\begin{array}{l}\text { Overall } \\
\mathbf{N}(\%)\end{array}$ & $\begin{array}{l}\text { Strongly } \\
\text { agree \% }\end{array}$ & $\begin{array}{c}\text { Agree } \\
\%\end{array}$ & $\begin{array}{c}\text { Neither } \\
\text { agree nor } \\
\text { disagree \% }\end{array}$ & $\begin{array}{c}\text { Disagree } \\
\%\end{array}$ & $\begin{array}{c}\text { Strongly } \\
\text { disagree } \\
\%\end{array}$ & $\mathbf{p}$ \\
\hline \multirow[t]{4}{*}{ Age } & $19-40$ & $9(8.8)$ & 11.1 & 22.2 & 22.2 & 33.3 & 11.1 & \multirow[t]{4}{*}{$0.65^{*}$} \\
\hline & $41-60$ & $30(29.4)$ & 3.3 & 10.0 & 50.0 & 16.7 & 20.0 & \\
\hline & $61-80$ & $58(56.8)$ & 12.1 & 15.5 & 44.8 & 17.2 & 10.3 & \\
\hline & $>80$ & $5(4.9)$ & 0.0 & 0.0 & 60.0 & 40.0 & 0.0 & \\
\hline \multirow[t]{2}{*}{ Gender } & Male & $66(64.7)$ & 6.1 & 18.2 & 45.5 & 21.2 & 9.1 & \multirow[t]{2}{*}{$0.47^{* *}$} \\
\hline & Female & $36(35.3)$ & 13.9 & 5.6 & 44.4 & 16.7 & 19.4 & \\
\hline \multirow{2}{*}{$\begin{array}{l}\text { Proximity } \\
\text { to hospital }\end{array}$} & GTA & $85(83.3)$ & 9.4 & 15.3 & 48.2 & 16.5 & 10.6 & \multirow[t]{2}{*}{$0.006^{* *}$} \\
\hline & $\begin{array}{c}\text { Outside } \\
\text { GTA }\end{array}$ & $17(16.7)$ & 5.9 & 5.9 & 29.4 & 35.3 & 23.5 & \\
\hline \multirow{5}{*}{$\begin{array}{l}\text { Type of } \\
\text { visit }\end{array}$} & First visit & 19 (18.6) & 21.1 & 10.5 & 42.1 & 15.8 & 10.5 & \multirow[t]{5}{*}{$0.37^{*}$} \\
\hline & $\begin{array}{l}\text { Routine } \\
\text { Followup }\end{array}$ & $54(52.9)$ & 3.7 & 14.8 & 44.4 & 20.4 & 16.7 & \\
\hline & $\begin{array}{c}\text { Followup } \\
\text { results }\end{array}$ & $11(10.7)$ & 10.0 & 0.0 & 80.0 & 10.0 & 0.0 & \\
\hline & $\begin{array}{c}\text { Discuss } \\
\text { procedure }\end{array}$ & $13(12.7)$ & 7.1 & 21.4 & 35.7 & 21.4 & 14.3 & \\
\hline & Other & $5(4.9)$ & 20.0 & 20.0 & 20.0 & 40.0 & 0.0 & \\
\hline
\end{tabular}

${ }^{*}$ Chi-squared test; ${ }^{* *}$ Mann Whitney U-test. 


\begin{tabular}{|c|c|c|c|c|}
\hline Predictor & $\begin{array}{c}\text { Unadjusted } \\
\text { OR } \\
(95 \% \mathrm{CI}) \\
\end{array}$ & $\mathbf{p}$ & $\begin{array}{l}\text { Adjusted OR } \\
\quad(95 \% \mathrm{CI})\end{array}$ & $\mathbf{p}$ \\
\hline Age & $\begin{array}{c}0.99 \\
(0.97-1.02)\end{array}$ & 0.72 & $\begin{array}{c}0.99 \\
(0.97-1.02)\end{array}$ & 0.64 \\
\hline Gender (reference $=$ female $)$ & $\begin{array}{c}0.75 \\
(0.36-1.59)\end{array}$ & 0.45 & $\begin{array}{c}0.76 \\
(0.34-1.71)\end{array}$ & 0.51 \\
\hline $\begin{array}{l}\text { Proximity to hospital (reference }= \\
\text { outside of GTA) }\end{array}$ & $\begin{array}{c}0.32 \\
(0.12-0.83)\end{array}$ & 0.02 & $\begin{array}{c}0.29 \\
(0.11-0.78)\end{array}$ & 0.01 \\
\hline Type of visit - First visit & $\begin{array}{c}0.97 \\
(0.16-5.91)\end{array}$ & 0.97 & $\begin{array}{c}1.13 \\
(0.18-7.21)\end{array}$ & 0.90 \\
\hline Type of visit - Routine followup & $\begin{array}{c}2.02 \\
(0.37-10.88)\end{array}$ & 0.42 & $\begin{array}{c}2.62 \\
(0.47-14.78)\end{array}$ & 0.28 \\
\hline Type of visit - Followup for results & $\begin{array}{c}1.12 \\
(0.16-8.04)\end{array}$ & 0.91 & $\begin{array}{c}1.79 \\
(0.23-13.81)\end{array}$ & 0.58 \\
\hline $\begin{array}{l}\text { Type of visit - Discuss a procedure } \\
\text { Reference }=\text { other }\end{array}$ & $\begin{array}{c}1.53 \\
(0.23-9.94)\end{array}$ & 0.66 & $\begin{array}{c}1.66 \\
(0.25-11.20)\end{array}$ & 0.60 \\
\hline
\end{tabular}

CI: confidence interval; OR: odds ratio. 
Patients' perspective of telephone visits during COVID-19

\begin{tabular}{|l|l|}
\hline Table 4. Examples of comments \\
\hline Participant comments & Examples \\
\hline Positive & $\begin{array}{l}\text { "It was a great experience! Since this was a first visit, and it } \\
\text { was essentially just a consult with some advice for monitoring } \\
\text { (i.e. not an intense appointment, no prescriptions, etc), it was } \\
\text { very easy and very convenient to do over the phone. I think it } \\
\text { would be a great idea to continue the option of phone } \\
\text { appointments when appropriate." }\end{array}$ \\
\cline { 2 - 3 } & $\begin{array}{l}\text { "As I had had a previous first visit with Dr. X and he/she had } \\
\text { prescribed certain actions this was a second consultation. This } \\
\text { was a follow up to see if the actions were of benefit and to work } \\
\text { forward. The discussion on the telephone was extremely } \\
\text { informative and was a great alternative to: } 1 \text {. driving all the way } \\
\text { from my place to the hospital. } 2 \text {. paying \$25 for parking The } \\
\text { information was what I would of got in person." }\end{array}$ \\
\hline "I was not having any problems, it was just one of my twice \\
yearly follow ups. I think the phone call was fine for that. But if \\
I was having a problem or was in discomfort I would rather do \\
it in person."
\end{tabular}

